\title{
HOW THE CO-CREATIVE PROCESS AFFECTS CONCEPT FORMATION
}

\author{
Matsumae, Akane (1); \\ Raharja, Ferdi Trihadi (1); \\ Ehkirch, Quentin (2); \\ Nagai, Yukari (3) \\ 1: Kyushu University; \\ 2: University of Technology of Belfort-Montbéliard; \\ 3: Japan Advanced Institute of Science and Technology
}

\begin{abstract}
The importance of forming concepts in one's mind has been argued from various perspectives in design studies. This experimental study examines how the co-creative process affects concept formation considering its depth.

The authors conducted a learning experiment applying three processes; non-interactive (NI), interactive but non-co-creative (NC), and interactive and co-creative processes (C). To evaluate whether and how deep the concept is formed in the examinee's mind, mimetic Japanese words, which contain several different explicit concepts underlying a certain integrated implicit concept, were chosen as learning materials. The examinees without any knowledge about mimetic Japanese words were gathered globally and the experiment was conducted fully online using English. Examinees were tested several times to measure how they had formed these concepts for comparing the processes.

The findings suggest that the co-creative process enhances the depth of concept formation: involvement load and willingness to participate in the co-creative process lead to deeper concept formation.
\end{abstract}

Keywords: Concept Formation, Creativity, Participatory design, Design for interfaces, Learning design

Contact:

Matsumae, Akane

Kyushu University

Faculty of Design

Japan

matsumae@design.kyushu-u.ac.jp

Cite this article: Matsumae, A., Raharja, F. T., Ehkirch, Q., Nagai, Y. (2021) 'How the Co-Creative Process Affects Concept Formation', in Proceedings of the International Conference on Engineering Design (ICED21), Gothenburg, Sweden, 16-20 August 2021. DOI:10.1017/pds.2021.439 


\section{INTRODUCTION}

How does the co-creative process affect concept formation? The importance of forming concepts in one's mind has been argued from various perspectives in design studies. Concept depth has also been regarded as being important in non-verbal shared mental representation in language-based design team communication (Dong, 2005) and as the heart of impression (Fasiha et al., 2010). The formation of concepts demands creative thinking (Casakin, 2007), and thinking patterns in which explicit and 'inexplicit' concepts are continuously intertwined lead to creative design ideas (Taura et al., 2012). Experiments have revealed that the co-creative process, which by definition includes transferring tacit knowledge to tacit knowledge, increases shared contexts and engagement (Matsumae and Nagai, 2020). In this study, the authors applied both co-creative and non-co-creative processes to a learning experiment and compared their results. Referring to the bouba/kiki effect (Ramachandran, 2001), mimetic Japanese words, which contain several different explicit concepts underlying a certain integrated implicit concept, were chosen as learning materials because they allow clear evaluation of whether and how deep the concept is formed in the subject's mind. Based on the related studies that follow, this study examined the hypothesis that, with the involvement load (Hulstijn \& Laufer, 2001) and cognitive load required during the co-creative process, the transfer of contextual understanding (tacit knowledge) within learned words will be enhanced, resulting in deeper concept formation and greater retention.

\subsection{Interactivity}

The study of interactivity has broadened to the point that interactivity means different things in different fields, with different examinees and in different contexts (McMillan, 2002). However, it is clear, at least in the context of learning, that interactivity can enhance learning (Kettanurak, 2001; Moreno \& Valdez, 2005; Smeets \& Bus, 2012) beyond results obtained with conventional methods. Moreno \& Mayer (2007) defined interactivity as a characteristic of learning environments that enables multidirectional communication, whereby the goal of the learner's actions needs to be kept consistent with the instructional goal. In the present research, interactivity is somewhat similarly defined as a characteristic that allows a learner to engage in multidirectional communication. In earlier years, faceto-face interaction was seen as the highest form of interactivity, and interactivity could be interpreted as the degree to which a system exhibits first-personness.

\subsection{Co-creativity}

Matsumae \& Nagai (2018) defined co-creativity as a shared motivation among individuals to realize and develop their concepts, which includes the SECI model socialization phase (transferring tacit knowledge to tacit knowledge). A recent finding revealed that the co-creative process has the effect of increasing the value of shared contextual knowledge and co-creation (Mori et al., 2021). For this research, the factor of "contextual understanding" was added to evaluate the depth of a concept formed in the learner's mind. The co-creative process was theorized as helping to enhance contextual understanding between a computer program that is prepared with vocabulary knowledge and the learner. In this research, co-creation acts as a subcategory of interaction, co-creative interaction and non-co-creative interaction.

\subsection{Cognitive load}

Cognitive load falls into three types: intrinsic load, extraneous load, and germane load. Intrinsic load is the effort associated with a specific topic, extraneous load refers to the way information or tasks are presented to a learner, and germane load refers to the work put into creating a permanent store of knowledge. Sweller (1994) suggested that extraneous cognitive load that interferes with learning is only a problem under conditions of high cognitive load caused by high element interactivity. Also, high cognitive load can result in a diminishing capacity to learn (Plass et al., 2003). In the present research, cognitive load is measured to track the amount of working memory resources used in each learning method. It is important to know whether an examinee has borne excessive extraneous load while participating in the experiment, as this might result in a diminished capacity to learn. 


\section{METHODOLOGY}

\subsection{The experimental methodology}

\subsubsection{Experimental Procedure}

The procedure was separated into three learning methods: non-interaction (NI), non-co-creative interaction (NC), and co-creative interaction (C). Method NI served as the conventional learning method, where all information was laid out as if it was on paper. This method was needed to calculate the standardized results. Method NC revealed how the learners performed without the co-creative process, and was needed for comparison with method C. Method C showed how the learners performed with the addition of co-creative process.

The examinees were separated into two groups based on the order of learning process to avoid the effects of order, P1 (NI - NC - C) and P2 (NI - C - NC). Each learning method was followed by a test to see how much the examinees learned from each method. The learners' abilities were tested for four criteria: form, meaning, use, and contextual understanding. A five-grade scale questionnaire was given after each test to determine the examinee's cognitive load. At the very end of the experiment, examinees were given a questionnaire by which they could provide their subjective feedback about what they thought/felt in regard to each method followed by the retention test, which is a test of short retention of all of the words learned (Figure 1).

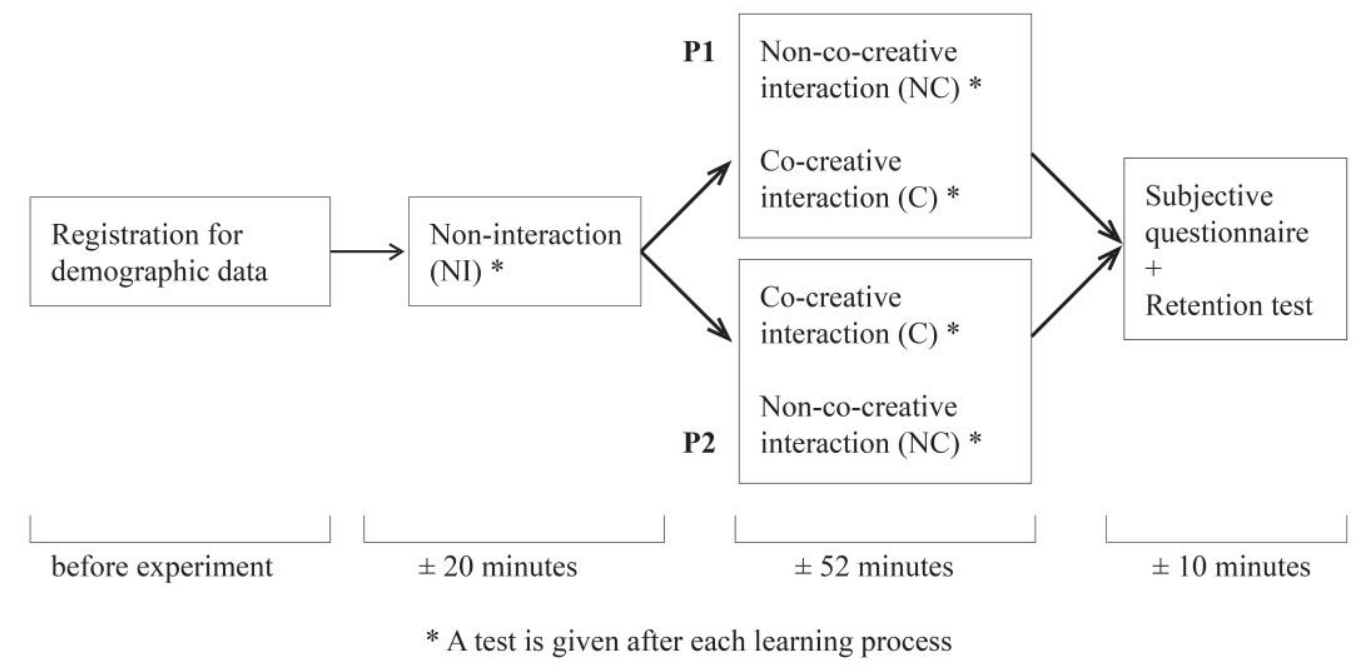

Figure 1. Flow of the experimental procedure

\subsubsection{Examinees}

Thirty-seven healthy examinees participated in the experiment (19 examinees for P1 and 18 examinees for P2), with ages ranging between 14 and 42 years old. 57\% were female and $43 \%$ were male. $70 \%$ had studied Japanese for less than a year, 27\% had studied Japanese for more than a year and 3\% had a Japanese proficiency level of N3 or more. Since the experiment used English, the examinees' English proficiency was also considered, with 70\% having used English for more than 5 years, 24\% having used English for less than 5 years, and $6 \%$ being native speakers. While some $90 \%$ of the examinees were Indonesian, the experiment faced no problems caused by language differences.

\subsubsection{Vocabulary Learning Materials, Mimetic Japanese Words}

For learning materials, the authors opted to use mimetic Japanese words that contain an integrated tacit concept with multiple explicit meanings that depend on context. They were chosen with the assumption that they would have been less likely to have been encountered by the examinees previously. This turned out to be a justified assumption, as 23 of the examinees $(n=37)$ did not know any mimetic Japanese words beforehand, and only 2 out of 14 examinees that knew some beforehand were able to say at least 3 out of 15 chosen words when asked about the mimetic Japanese words they knew. Mimetic Japanese 
words tend to be very consistent in their use of four syllables (kirakira, gatagata, gangan, etc.), and this particular trait was helpful in diminishing the usual difficulty experienced when facing foreign words, as longer foreign words tend to be harder to memorize than shorter foreign words (Ono, 2017). Mimetic Japanese words are commonly divided into two main categories: the mimicry of sounds and mimicry of conditions. The authors selected mimetic Japanese words in the latter category to get a better grasp of tacit knowledge from the authorised Japanese database (NIJLL). Chun \& Plass (1996) pointed out that words annotated with pictures and texts resulted in higher scores. Their research offered the view that it is easier to learn the word if it is associated with actual objects or images. In accordance with this, pictures and texts were used in this research as components that needed to be learned, and which the subjects were later tested on.

Examinees were given the task of acquiring 15 mimetic Japanese words. Each word had 3 meanings, with 3 example sentences and 3 pictures given per meaning, and a visual cue accompanying the word wherever such a cue was possible (Figure 2).

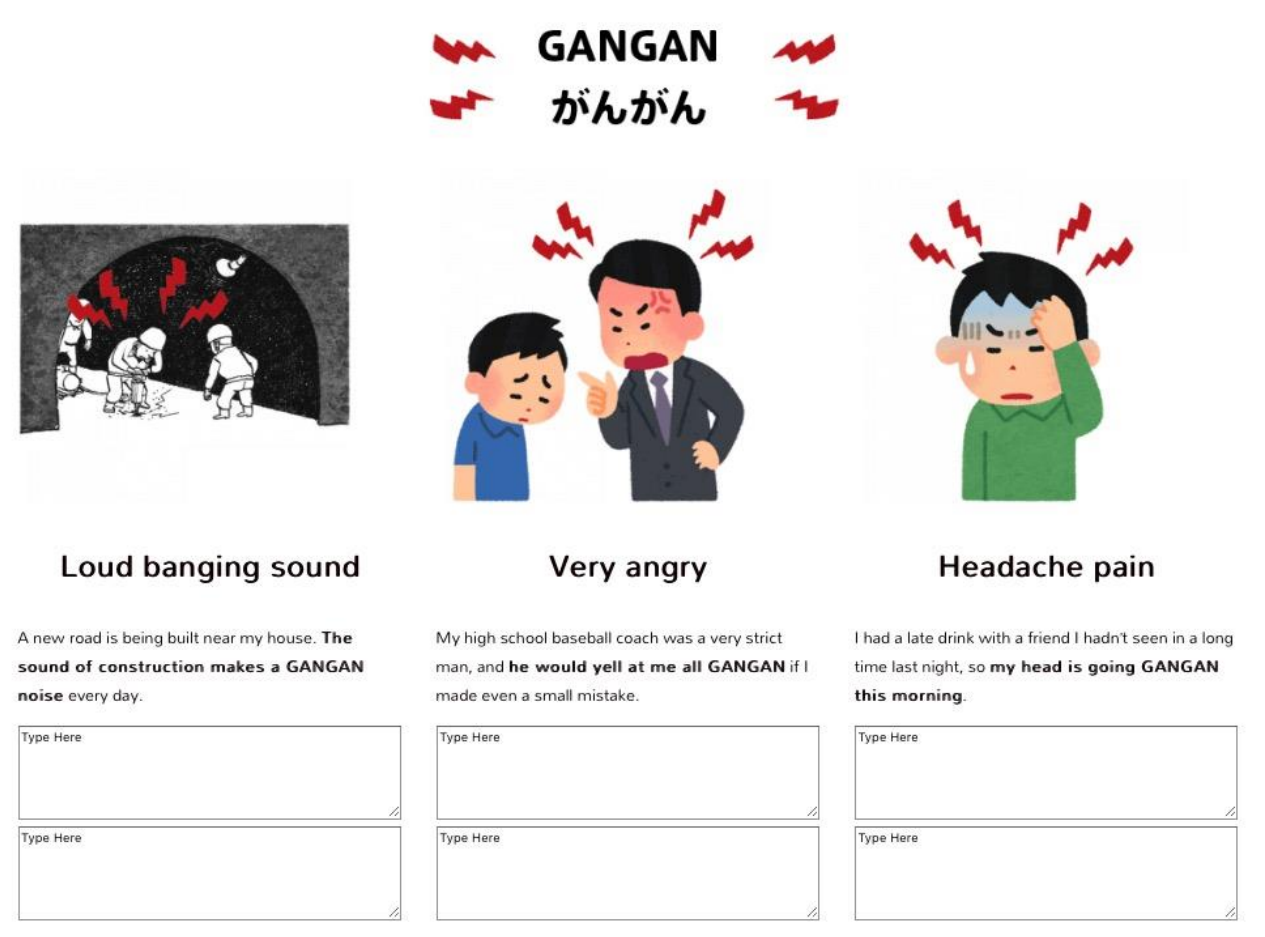

Figure 2. Example of vocabulary learning material (NI)

\subsubsection{Learning Methods}

Examinees were divided into three groups participating on different days, and each group was given learning methods with different wordsets. This was to diminish the influence of the words chosen over the learning method. The differences in how information was presented in each method are described in Table 1.

In co-creative method $\mathrm{C}$, examinees were required to create and type a sentence, after which they were given the example sentence to read. They then created and typed another example sentence. From the examinee's point of view, they were co-creating the sentence. Each method was carefully designed to be identical to the other methods except for the factor to be compared, avoiding unnecessarily added variables that would need to be considered. To minimize the effect of typing, for instance, each method required typing twice to be consistent with the other two methods. Since method C required the examinees to type twice in order to enable the sense of co-creation, other examinees were also made to type some part of the example sentences twice in both NI and NC methods.

During the learning session, examinees were not allowed to take notes; all examinees needed to undergo the same process for their data to be compared equally. 
Table 1. Learning methods

\begin{tabular}{|l|l|l|l|}
\hline & $\begin{array}{l}\text { Non-interaction } \\
(\mathrm{NI})\end{array}$ & $\begin{array}{l}\text { Non-co-creative interaction } \\
(\mathrm{NC})\end{array}$ & Co-creative interaction (C) \\
\hline \hline Images & Shown & Shown & Shown \\
\hline Meanings & Shown & Shown & Shown \\
\hline $\begin{array}{l}\text { Example } \\
\text { sentences }\end{array}$ & Shown & Could hide or show & $\begin{array}{l}\text { Shown after examinee created } \\
\text { first sentence }\end{array}$ \\
\hline Typing & $\begin{array}{l}\text { Typed some part of the } \\
\text { example sentence twice. }\end{array}$ & $\begin{array}{l}\text { Typed some part of the } \\
\text { example sentence twice. }\end{array}$ & $\begin{array}{l}\text { Typed twice: the first sentence } \\
\text { the examinee created, and then } \\
\text { the second sentence after } \\
\text { returning the example sentence. }\end{array}$ \\
\hline
\end{tabular}

\subsubsection{Vocabulary Tests}

Nation (2001) noted three criteria for knowing a word, namely form, meaning and use; it is not until all three criteria are met that one acquires new vocabulary. In this research, the fourth criteria of "contextual understanding" had been added, to evaluate the depth of a concept formed by considering the degree of transferred tacit knowledge contained within each word.

Retention is measured to evaluate how deeper the concept is formed in the subject's mind. One such way is the involvement load theory by Hulstijn \& Laufer (2001), which stated that the greater the involvement load, the better the retention. In their experiment, Hulstijn \& Laufer (2001) separated retention into shortterm retention, which was the term used to measure retention immediately after a learning task, and longterm retention, which was separated by one to two weeks. In the present research, the authors use "retention" to refer to short-term retention, measured by a test at the end of the experiment.

After every learning method, examinees were given a test to check vocabulary acquisition. There were two different types of vocabulary tests, as shown below (Table 2).

Table 2. Vocabulary tests

\begin{tabular}{|l||l|l|}
\hline & Test for each method & Short Retention Test \\
\hline When the test was given & $\begin{array}{l}\text { After each method (3 } \\
\text { times with different } \\
\text { wordsets) }\end{array}$ & At the end of the experiment \\
\hline $\begin{array}{l}\text { FORM - Type the words } \\
\text { learned. }\end{array}$ & $\begin{array}{l}5 \text { words learned from the } \\
\text { method }\end{array}$ & All 15 words learned from all methods \\
\hline $\begin{array}{l}\text { MEANING - Choose three } \\
\text { correct meanings from the } \\
\text { given text options. }\end{array}$ & $\begin{array}{l}3 \text { random questions out of } \\
5 \text { words }\end{array}$ & 5 random questions out of 15 words \\
\hline $\begin{array}{l}\text { USE - Create sentences based } \\
\text { on the presented images using } \\
\text { the words learned. }\end{array}$ & $\begin{array}{l}3 \text { random questions out of } \\
5 \text { words }\end{array}$ & 5 random questions out of 15 words \\
\hline $\begin{array}{l}\text { CONTEXT - Choose pictures } \\
\text { and type the matching words } \\
\text { from an integrated illustration. }\end{array}$ & $\begin{array}{l}11 \text { questions, with 7 } \\
\text { answers and } 4 \text { bluffs }\end{array}$ & 16 questions, with 10 answers and 6 bluffs \\
\hline QUESTIONNAIRE & Cognitive load (after test) & Subjective opinion on methods (before test) \\
\hline
\end{tabular}


The images used for questions covering "use" were the same images used for the learning methods, while the images used for "context" were different images that contained the same tacit knowledge. These different sets of images were combined into what is called integrated illustration, and there were three of these, one for each method. This was needed because examinees might remember the image because of a feature in the image, and not because of the context. Therefore, in order to test contextual understanding, a different set of illustrations containing the same messages was used. As an extra layer to test contextual understanding, some bluff questions were also added. Examinees had to type the number associated with each image and the corresponding word, while bluffs could just be skipped (e.g.: 1-gatagata, 2-kirakira, 4-boroboro, etc.). On the retention test, not all words were tested on "meaning" and "use" because the goal was to be as close as possible to the previous tests and to avoid making the experiment too long. The authors decided to randomize the selection of 5 words for "meaning" and 5 pictures for "use" as the middle point between all possibilities (same number as the number of mimetic Japanese words in a wordset).

\subsection{Evaluation methodology}

Data obtained from the experiment were analysed to evaluate how each variable affected another variable in vocabulary acquisition. The table below shows why and how each data set was collected (Table 3).

Table 3. Measures used for evaluation

\begin{tabular}{|c|c|c|c|}
\hline Type of data & $\begin{array}{l}\text { Measured } \\
\text { variable }\end{array}$ & Why & How \\
\hline Demographic & $\begin{array}{l}\text { Age, Gender, } \\
\text { Language level }\end{array}$ & $\begin{array}{l}\text { Evaluates whether a certain } \\
\text { demographic factor have any } \\
\text { effect }\end{array}$ & Questionnaire \\
\hline \multirow{4}{*}{ Score } & $\begin{array}{l}\text { Form of the } \\
\text { word }\end{array}$ & $\begin{array}{l}\text { Evaluates knowledge transfer of } \\
\text { forming the words }\end{array}$ & Type words learnt \\
\hline & $\begin{array}{l}\text { Meaning of the } \\
\text { word }\end{array}$ & $\begin{array}{l}\text { Evaluates knowledge transfer of } \\
\text { word meanings }\end{array}$ & $\begin{array}{l}\text { Choose } 3 \text { matching } \\
\text { meanings }\end{array}$ \\
\hline & Use of the word & $\begin{array}{l}\text { Measures the knowledge transfer } \\
\text { of using the words }\end{array}$ & $\begin{array}{l}\text { Make a sentence based on a } \\
\text { picture }\end{array}$ \\
\hline & $\begin{array}{l}\text { Context of the } \\
\text { word }\end{array}$ & $\begin{array}{l}\text { Measures the knowledge transfer } \\
\text { of contextual understanding of } \\
\text { the words (tacit knowledge) }\end{array}$ & $\begin{array}{l}\text { Pick some illustrations out } \\
\text { of combined illustrations } \\
\text { and type matching words. }\end{array}$ \\
\hline \multirow[t]{3}{*}{$\begin{array}{l}\text { Subjective } \\
\text { Opinion }\end{array}$} & Cognitive load & $\begin{array}{l}\text { Measures the mental effort in } \\
\text { each learning method }\end{array}$ & $\begin{array}{l}\text { Questionnaire on test for } \\
\text { each method }\end{array}$ \\
\hline & $\begin{array}{l}\text { Preferred } \\
\text { method }\end{array}$ & $\begin{array}{l}\text { Investigates how examinees feel } \\
\text { about their preferred method }\end{array}$ & $\begin{array}{l}\text { Questionnaire at the end of } \\
\text { the experiment }\end{array}$ \\
\hline & $\begin{array}{l}\text { Comparison of } \\
\text { method }\end{array}$ & $\begin{array}{l}\text { Investigates how examinees feel } \\
\text { about each method }\end{array}$ & $\begin{array}{l}\text { Questionnaire at the end of } \\
\text { the experiment }\end{array}$ \\
\hline \multirow[t]{2}{*}{$\begin{array}{l}\text { Screen Video } \\
\text { Recording }\end{array}$} & $\begin{array}{l}\text { Time used for } \\
\text { learning }\end{array}$ & $\begin{array}{l}\text { Knowing whether or not they } \\
\text { have time limit may change the } \\
\text { way they learn }\end{array}$ & $\begin{array}{l}\text { Time annotations on video } \\
\text { recording }\end{array}$ \\
\hline & $\begin{array}{l}\text { Delay between } \\
\text { learning and test }\end{array}$ & $\begin{array}{l}\text { Evaluates if the item learned is in } \\
\text { short term memory or long-term } \\
\text { memory }\end{array}$ & $\begin{array}{l}\text { Time annotations on video } \\
\text { recording }\end{array}$ \\
\hline
\end{tabular}


The retention of words learned was examined only for the short term (between 50 minutes to 2 hours), and this range was selected based on how the quickest and slowest examinees performed from the beginning of the experiment until they started the retention test.

\subsubsection{Effect of different wordset}

Each learning method used different wordsets so that the examinees would not learn the same words multiple times. Wordsets were chosen with balance in mind, and with the help of someone who is experienced in learning the language. The effect of different wordsets was confirmed after the experiment, and proved to be minimal.

\subsubsection{Standardization}

To minimize the effect of differences in learning ability among the examinees (some examinees are better at learning than others), the results of method NI were used as a standard for how an examinee would perform normally, to see how methods $\mathrm{NC}$ and $\mathrm{C}$ performed when the two were compared. A standardized calculation was used to calculate every variable analysed.

\subsubsection{Duration of learning vocabulary}

Time plays a huge role in memorization. To avoid interfering with the learning capacity of the examinees, the authors decided to not set time limits during the experiment. This was also done to avoid the pressure a time limit imposes and to allow the examinees to proceed at their own pace, with an aim to help the examinees perform normally. However, the time used by the examinees was considered in the analysis.

\subsubsection{Cognitive load}

The data for each examinee's cognitive load was collected with a form that required the examinees to provide their own subjective evaluation of the load. While a nine-grade scale is usually used for this evaluation method, this study used a five-grade scale instead, since it was deemed more appropriate for answering several questions related to cognitive load to get a clearer comparison between the three methods.

\subsubsection{Subjective comments}

Subjective comments were collected by questionnaire just before the final retention test. Each examinee's preferred method was analysed and compared with their actual performance. This was to determine whether their opinion or preference might have any effect on the score they attained. Opinions comparing the methods were solicited to obtain a more in-depth look at how the examinees felt about each method and their differences.

\section{RESULTS}

The effect of different wordsets was examined before any other analysis. Standardized results of different wordsets showed no significant differences, allowing the negation of any influence from this factor on the results afterward $(\mathrm{P}<.07)$. The effect of learning order was also examined. There were two different learning orders, P1 (NI-NC-C) and P2 (NI-C-NC), which showed no significant effect $(\mathrm{P}<.114)$.

Table 4. Standardized result of test scores

\begin{tabular}{|l|l|l|l|l|l|}
\hline & Form & Meaning & Use & Context & Retention \\
\hline Non-Co-creative (NC) & 1.05 & 1.05 & 1.24 & 1.14 & 1.48 \\
\hline Co-creative (C) & 1.03 & 0.98 & 1.13 & 1.45 & 1.53 \\
\hline
\end{tabular}

As shown above, method NC always performed slightly better than method $\mathrm{C}$ with regard to vocabulary acquisition criteria as defined by Nation, form, meaning, and use. On the other hand, although it was a very slight difference, $\mathrm{C}$ exceeded $\mathrm{NC}$ in context and retention, which are the two variables that were 
expected to be enhanced with the addition of the co-creative process (Table 4). However, no clear tendency could be found in any of the comparisons.

The cognitive load in method $\mathrm{C}$ was greatest, as examinees were required to create sentences (Figure 3). Method $\mathrm{C}$ was also where the examinees spent the most time on average, as they had to engage in more cognitive activities.

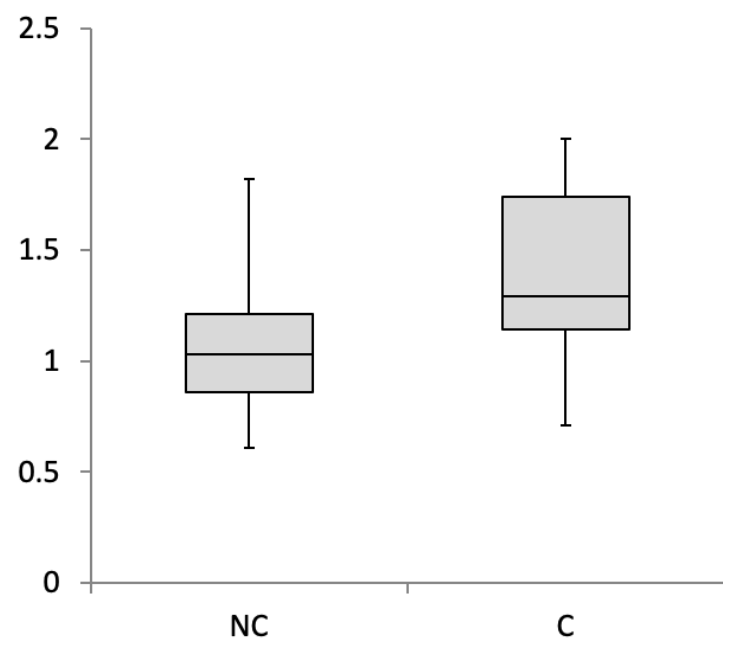

Figure 3. Standardized result of cognitive load

\section{DIscussion}

\subsection{Discussion}

To be able to compare the methods while focusing only on C \& NC, the experiment was designed to avoid added variables as much as possible. Also, the experiment was designed to be as short as possible, considering the burden that the examinees might experience. However, these decisions might have impacted the data obtained, since the data were insufficient to reveal any clear tendency on how the co-creative process affects concept formation. This also made the experiment considerably easier than it might have been, and there were a number of examinees who got perfect scores on both $\mathrm{NC}$ and C. The authors determined that examinees with perfect scores on both $\mathrm{NC}$ and $\mathrm{C}$ could not be evaluated correctly, and they were removed from the evaluation. Other than test scores, the effects of several other factors were examined, such as the effect of different wordsets, order of learning method, cognitive load and duration. These were analyzed to see how the addition of the co-creative process affects concept formation. Based on theoretical studies, the addition of the co-creative process to vocabulary acquisition was expected to enhance the transfer of contextual understanding, resulting in better retention. While no clear tendency was found, the areas where $\mathrm{C}$ performed better are consistent with this hypothesis (context and retention). While method $\mathrm{C}$ did, in fact, generate better scores in the context test and retention test, it was not significant enough to be relied on as evidence to support the statement that the co-creative processes enhance contextual understanding and retention.

However, these findings can be regarded as guidelines for future experiments. It is hoped that a clearer tendency will come to light with the improvement of clearer differences between method, difficulty, and a longer period of retention. Too many examinees had a perfect score on both methods NC and C, so the addition of more words or more complicated tasks on the tests should be considered to help increase the difficulty of the tests, avoiding the possibility of perfect scores and enabling better analysis. An appropriate period to examine the retention effect in the weeks or even months after the learning process might give better insight as to whether method $\mathrm{C}$ is indeed more effective for both short- and long-term retention. Increasing the number of examinees would also be a welcome addition to provide more reliable results.

\subsection{Involvement in co-creative learning}

A part of the subjective questionnaire asked which method the examinee preferred. The preferred method was compared to the best score obtained out of the three methods, and the result is shown in Figure 4. A matched high score means that the method with the highest scores obtained is also the 
preferred method, while a mismatched score means that method with the highest scores out of the three methods is not the preferred method. As method $\mathrm{C}$ requires greater involvement load, cognitive load, and time, it was thought that the examinees who preferred $\mathrm{C}$ liked it because of these factors and how they contribute toward their learning. This results in data showing that those who are engaged in the process are more likely to earn the best score on C. This is in contrast with method NI, as it can be assumed that those who prefer NI chose it because it was the easiest, and not because it was helpful in enhancing the learning process. This assumption is supported by the high percentage of mismatched high scores. This result can also be seen as evidence that method NI and C were designed accordingly, since NI required the least involvement, while $\mathrm{C}$ required the most. An examinee who prefers method $\mathrm{C}$, which requires more involvement load and cognitive load, is more likely to obtain better results with it; by choosing $\mathrm{C}$ as the preferred method, the examinee shows a willingness to be involved in the process.

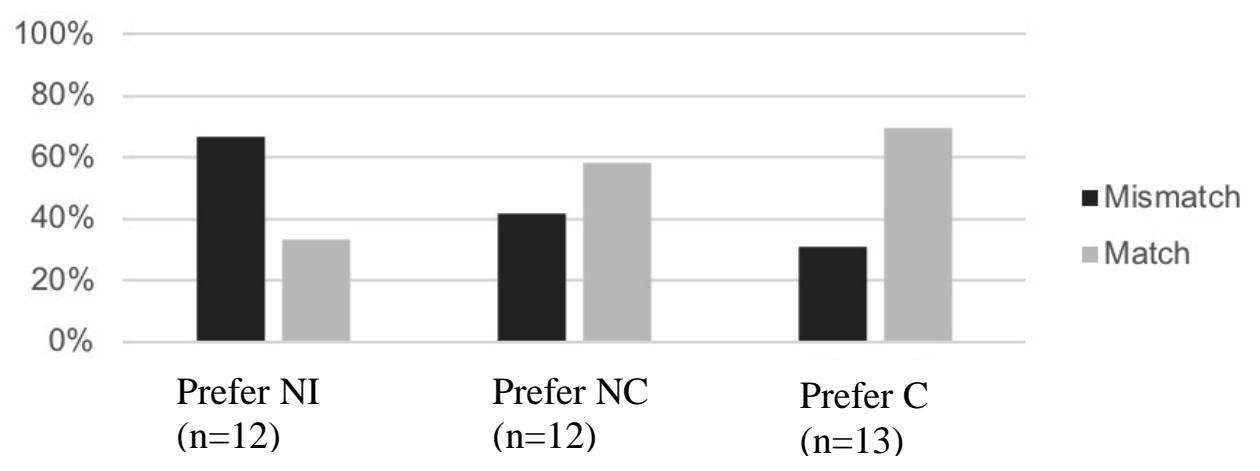

Figure 4. Preferred method compared to method with best score

\section{CONCLUSION}

The purpose of this study was to examine how the co-creative process affects concept formation. The results were analysed to help elucidate the effects generated with the existence of co-creative factors. By understanding these effects, insight was provided into how the co-creative process can enhance concept formation. The addition of the co-creative process demanded more time and a greater cognitive load from the examinees. These results suggest that the co-creative process, though somewhat inefficient, would assist in forming deeper concept formation. This would be in agreement with what Mori wrote about the co-creative process improving the value of contextual knowledge among stakeholders.

\subsection{Findings}

- The depth of concept formation (contextual knowledge and knowledge retention) where the cocreative process performed better are consistent with the hypothesis.

- Examinees who chose co-creative process as their preferred method also obtained their best score in co-creative learning. Involvement load and willingness to participate in co-creative process lead to concept formation.

\subsection{Limitations and future research}

- The tests and learning materials were deemed to be too easy. This hindered the analysis of how examinees performed, because it limited the possibility of looking at how far each examinee might have gone beyond their current perfect score.

- The immediate short-term retention test should be accompanied by a delayed long-term retention test, separated by weeks, to see which method has the most effective short-term/long-term retention.

- This research was executed completely online. It is hoped that the experiment can be executed face-to-face to ensure examinees are present in the same environment with the same equipment, since differences in the used devices and environments could add an extraneous cognitive load. 


\section{ACKNOWLEDGMENTS}

This work was supported by JSPS KAKENHI Grant Number JP20K20119. The authors also appreciate National Institute for Japanese Language and Linguistics for its Mimetic Japanese Words database and Gengoya for their support in gathering examinees and providing webpages to conduct the experiment.

\section{REFERENCES}

Casakin, H. P. (2007). Factors of metaphors in design problem-solving: Implications for design creativity. International Journal of Design, 1(2), 21-33.

Chun, D. M., \& Plass, J. L. (1996). Effects of Multimedia Annotations on Vocabulary Acquisition. Modern Language Journal, 80(2), 183-198. https://doi.org/10.1111/j.1540-4781.1996.tb01159.x

Dong, A. (2005). The latent semantic approach to studying design team communication, Design Studies, 26(5), 445-461. https://doi.org/10.1016/j.destud.2004.10.003.

Fasiha, M. Y. N., Sakayama, Y., Yamamoto, E., Taura, T., \& Nagai, Y. (2010). Understanding the nature of deep impression by analyzing the structure of virtual impression networks, Proceedings of International Design Conference, DESIGN, 1827-1836.

Hirschel, R., \& Fritz, E. (2013). Learning vocabulary: CALL program versus vocabulary notebook. System, 41(3), 639-653. https://doi.org/10.1016/j.system.2013.07.016

Hulstijn, J. H., \& Laufer, B. (2001). Some Empirical Evidence for the Involvement Load Hypothesis in Vocabulary Acquisition. Language Learning, 51(3), 539-558. https://doi.org/10.1111/0023-8333.00164

Kettanurak, V. (Nui), Ramamurthy, K., \& Haseman, W. D. (2001). User attitude as a mediator of learning performance improvement in an interactive multimedia environment: an empirical investigation of the degree of interactivity and learning styles. International Journal of Human-Computer Studies, 54(4), 541583. https://doi.org/10.1006/ijhc.2001.0457

Matsumae, A., \& Nagai, Y. (2018). The function of co-creation in dynamic mechanism of intersubjectivity formation among individuals. Proceedings of International Design Conference, DESIGN, 4, 1925-1936. https://doi.org/10.21278/idc.2018.0141

Matsumae, A., Matsumae, S., \& Nagai, Y. (2020). Dynamic Relationship Design of Knowledge Co-Creating Cluster: Traditional Japanese Architectural Industry. SN Applied Sciences, Systems and Technologies, 2(443). https:// doi.org/10.1007/s42452-020-2209-2

McMillan, S. J. (2002). Exploring models of interactivity from multiple research traditions: users, documents, and systems. In L. Lievrouw, \& S. Livingston (Eds.), Handbook of New Media (pp. 162-182). London: Sage.

Moreno, R., \& Mayer, R. (2007). Interactive multimodal learning environments: Special issue on interactive learning environments: Contemporary issues and trends. Educational Psychology Review, 19(3), 309-326. https://doi.org/10.1007/s10648-007-9047-2

Moreno, R., \& Valdez, A. (2005). Cognitive Load and Learning Effects of Having Students Organize Pictures and Words in Multimedia Environments: The Role of Student Interactivity and Feedback. Educational Technology Research and Development, 53(3), 35-45.

Mori, S., Matsumae, A., \& Nagai, Y. (2021). Knowledge sharing structure of agricultural products: Case of kokuzoyuzu (citrus). Smart Innovation, Systems and Technologies, 198 SIST, 335-345. https://doi.org/10.1007/978-3-030-55374-6_33

Nation, I. S. P. (2001). Learning Vocabulary in Another Language. In Learning Vocabulary in Another Language. https://doi.org/10.1017/cbo9781139524759

Nonaka, I., Umemoto, K., \& Senoo, D. (1996). From information processing to knowledge creation: A paradigm shift in business management. Technology in Society, 18(2 SPEC. ISS.), 203-218. https://doi.org/10.1016/0160-791X(96)00001-2

Ono, T. (2017). Vocabulary Learning Through Computer Assisted Language Learning. Hitotsubashi Journal of Arts and Sciences, 58(1), 67-72. www.memrise.com

Plass, J. L., Chun, D. M., Mayer, R. E., \& Leutner, D. (2003). Cognitive load in reading a foreign language text with multimedia aids and the influence of verbal and spatial abilities. Computers in Human Behavior, 19(2), 221-243. https://doi.org/10.1016/S0747-5632(02)00015-8

Ramachandran, V.S., \& Hubbard, E.M. (2001). Synaesthesia - a window into perception, thought and language. Journal of Consciousness Studies, 8 (12), 3-34.

Smeets, D. J. H., \& Bus, A. G. (2012). Interactive electronic storybooks for kindergartners to promote vocabulary growth. Journal of Experimental Child Psychology, 112(1), 36-55. https://doi.org/10.1016/j.jecp.2011.12.003

Sweller, J. (1994). Cognitive load theory, learning difficulty, and instructional design. Learning and Instruction, 4(4), 295-312. https://doi.org/10.1016/0959-4752(94)90003-5 
Taura, T., Yamamoto, E., Fasiha, M.Y.N, Goka, M., Mukai, F., Nagai, Y., \& Nakashima, H. (2012) Constructive simulation of creative concept generation process in design: a research method for difficult-to-observe design-thinking processes, Journal of Engineering Design, 23:4, 297-321,

https://doi.org/10.1080/09544828.2011.637191

Wagner, E. D. (1994). In support of a functional definition of interaction. The American Journal of Distance Education, 8,6-29 


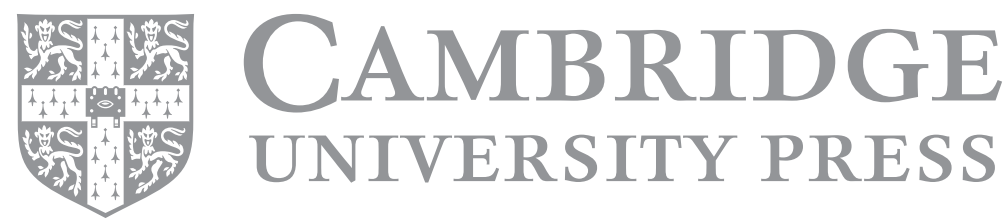

